\title{
Die $\mathfrak{A} \mathfrak{a t u r g e i d i d t e ~}$
}

in

ber Bulfofdulte umb in ten mittleren Rlaffen Der $\mathfrak{R e a l}=$ unb höberen Bürgerjoulen,

jux Bentţุu!t]

für Regrer unb @djüler, fo wie für Freulbe ber Miatur.

8ufanmengejtell unt bearbeitet

vil!

(ง. 2. sitter.

\section{(Erfter $\mathfrak{A} \mathfrak{f}$ fdult.}

3oplogie.

Bweiter Cuntus.

Die Sängethiere unto Bügel ber Seimath nebift ben

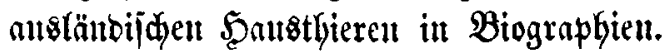

\section{Berlin.}

Druf unb Werlag vou Georg Beimer.

1858. 
